\title{
Passive Cooldown Performance of Integral Pressurized Water Reactor
}

\author{
Shoubao Dai, Chunnan Jin, Jingfu Wang, Yuxiang Chen \\ NO.703 Research Institute of China Shipbuilding Industry Corporation, Harbin, China \\ Email: daishoubao@126.com \\ Received January, 2013
}

\begin{abstract}
The design of an integral pressurized water reactor (IPWR) focuses on enhancing the safety and reliability of the reactor by incorporating a number of inherent safety features and engineered safety features. However, the characteristics of passive safety systems for the marine reactors are quiet different from those for the land nuclear power plant because of the more formidable and dangerous operation environments of them. This paper presents results of marine black out accident analyses. In the case of a transient, the passive residual heat removal system (PRHRS) is designed to cool the reactor coolant system (RCS) from a normal operation condition to a hot shutdown condition by a natural circulation, and the shutdown cooling system (SCS) is designed to cool the primary system from a hot shutdown condition to a refueling condition by a forced circulation. A realistic calculation has been carried out by using the RELAP5/MOD3.4 code and a sensitivity analysis has been performed to evaluate a passive cooldown capability. The results of the accident analyses show that the reactor coolant system and the passive residual heat removal system adequately remove the core decay heat by a natural circulation.
\end{abstract}

Keywords: An Integral Pressurized Water Reactor (IPWR); Passive Safety System; Styling; Natural Circulation

\section{Introduction}

Most of the primary circuit components of an integral pressurized water reactor (IPWR) are housed within a single reactor pressure vessel (RPV). This layout can provide the optimum configuration for adopting inherent and passive safety design. So they are suitable for the medium/small size nuclear power plants and marine nuclear systems. However, the characteristics of passive safety systems for the marine reactors are quiet different from those for the land nuclear power plant because of the more formidable and dangerous run environments of them. Consequently, in order to ensure the reliability and the security of the marine-used IPWR, it is of great importance to perform detailed investigation on the operation characteristics of their passive safety systems [1,2].

The IPWR with 100 MW capability is designed in this paper. Fundamental concept and general arrangement of the IPWR in this paper is based on the same principle of the Inherent Safe UZrHx Power Reactor [3] and the Russian ABV-6M IPWR [4]. This $100 \mathrm{MW}$ integral reactor adopts the arc plate fuels in core, casing once-through steam generator (OTSG), inherent safety improving features such as a large volume of the reactor coolant, a large negative moderator temperature coefficient, a low core power density, and a passive residual heat removal system (PRHRS). The major design parameters are summarized in Table 1. The Figure 1 shows a schematic diagram of the safety systems for the IPWR design. These safety systems are designed to meet the relevant redundancy and independency design requirements to ensure a high reliability and safety.

Table 1. Initial parameters for the system.

\begin{tabular}{lcc}
\hline \multicolumn{1}{c}{ System parameters } & Values & Unites \\
\hline Thermal power & 100 & $\mathrm{MW}$ \\
Reactor pressure vessel & & \\
Operating pressure & 14 & $\mathrm{MPa}$ \\
Coolant mass flow & 1500 & $\mathrm{t} / \mathrm{h}$ \\
Core inlet temperature & 235 & ${ }^{\circ} \mathrm{C}$ \\
Core outlet temperature & 286 & ${ }^{\circ} \mathrm{C}$ \\
Steam generator & & \\
Main steam flow rate & 160 & $\mathrm{t} / \mathrm{h}$ \\
Steam temperature & 263.84 & ${ }^{\circ} \mathrm{C}$ \\
Feedwater temperature & 150 & ${ }^{\circ} \mathrm{C}$ \\
Steam pressure & 2.943 & $\mathrm{MPa}$ \\
Tube outer diameter & $8 \times 1$ & $\mathrm{~mm}$ \\
Tube inner diameter & $10 \times 1.5$ & $\mathrm{~mm}$ \\
Tube length & 1.5 & $\mathrm{~m}$ \\
PRHRS & & \\
Coolant initial temperature & 24 & ${ }^{\circ} \mathrm{C}$ \\
Coolant initial pressure & 0.1013 & $\mathrm{MPa}$ \\
Tube inner diameter & $16 \times 1.2$ & $\mathrm{~mm}$ \\
Tube length & 1.6 & $\mathrm{~m}$ \\
Water temperature in tank & 24 & ${ }^{\circ} \mathrm{C}$ \\
Water pressure in tank & 0.1013 & $\mathrm{MPa}$ \\
\hline
\end{tabular}




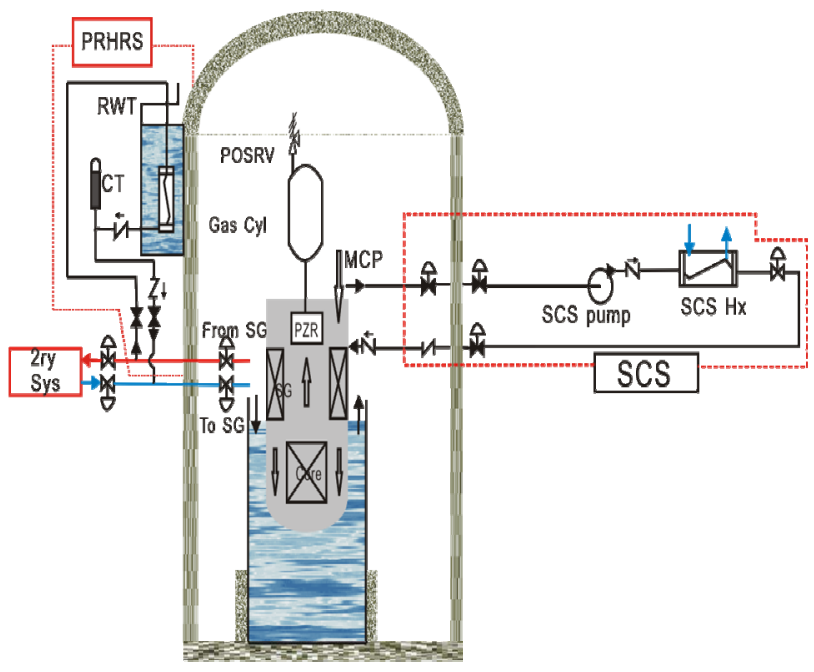

Figure 1. Schematic diagram of the safety system of IPWR.

\subsection{Passive Residual Heat Removal System (PRHRS)}

The PRHRS passively removes a core decay heat and a sensible heat by a natural circulation in case of an emergency condition such as unavailability of feed-water supply or marine black out. Besides, the PRHRS may also be used in case of long-term cooling for repair [5].

The IPWR can cool down the primary coolant from a normal operation to a hot shutdown using a passive safety system when the reactor is tripped while a loop-type commercial PWR cools down the coolant using an active system such as an auxiliary feed-water system. The active system can maintain a constant cooldown rate for the transient, however, the passive system is relatively difficult to maintain a constant value because a driving force reduces when a density difference between a hot and cold sides is small at the end of transient. Therefore, a cooldown analysis should be accomplished according to a well-defined methodology.

\subsection{Shutdown Cooling System (SCS)}

The shutdown cooling system is designed to remove a normal heat and a sensible heat in the reactor vessel from a hot shutdown to a refueling condition. When the reactor coolant system reaches $208^{\circ} \mathrm{C}$ of a coolant temperature and 2.3 $\mathrm{MPa}$ of its pressure, the shutdown cooling system cools the reactor coolant system to a refueling condition. The SCS includes a shutdown cooling pump, a heat exchanger, a water storage tank and valves. The SCS sucks up a coolant at the main coolant pump (MCP) suction duct, and then it discharges the coolant to the main coolant pump discharge region [6].

\section{Analysis Results}

To evaluate the passive cooldown capability of the IPWR in the case of marine black out accident, an analysis is performed by using the system analysis code, RELAP5/MOD3.4[7]. The nodalization for a passive cooldown analysis of the IPWR is shown in Figure 2.

The results of the cooldown analysis are presented. The marine black out accident begins after operating at full power for $100 \mathrm{~s}$. In the case of marine black out transient, the reactor is rapidly tripped by a trip signal, then the PRHRS isolation valve is opened and the MFIV/ MSIV are closed.

The mass flow rate in the primary loop drops immediately due to the main coolant pump coasting down on reactor trip. The natural circulation flow is well established after 8s as noticed in Figure 3. Due to sub-cooled water of residual heat exchanger (RHE) tubes entering OTSG, fluid temperature at the core inlet initially decreases, but reduced heat removal by the secondary system makes the core inlet fluid temperature increase. After 50s the core inlet fluid temperature begins to decrease gradually with decreased power. The core outlet temperature has the same trend as the core inlet temperature as shown in Figure 4. It is noted in the Figures 5 and $\mathbf{6}$ that the primary pressure and pressurizer level continues to decrease with reactor trip. The secondary pressure increases rapidly on reactor trip. It is because that initially tubes of the PRHRS is full of sub-cooled water, and PRHRS have no enough heat transfer area to condense the steam which is from OTSG, so the mass and energy

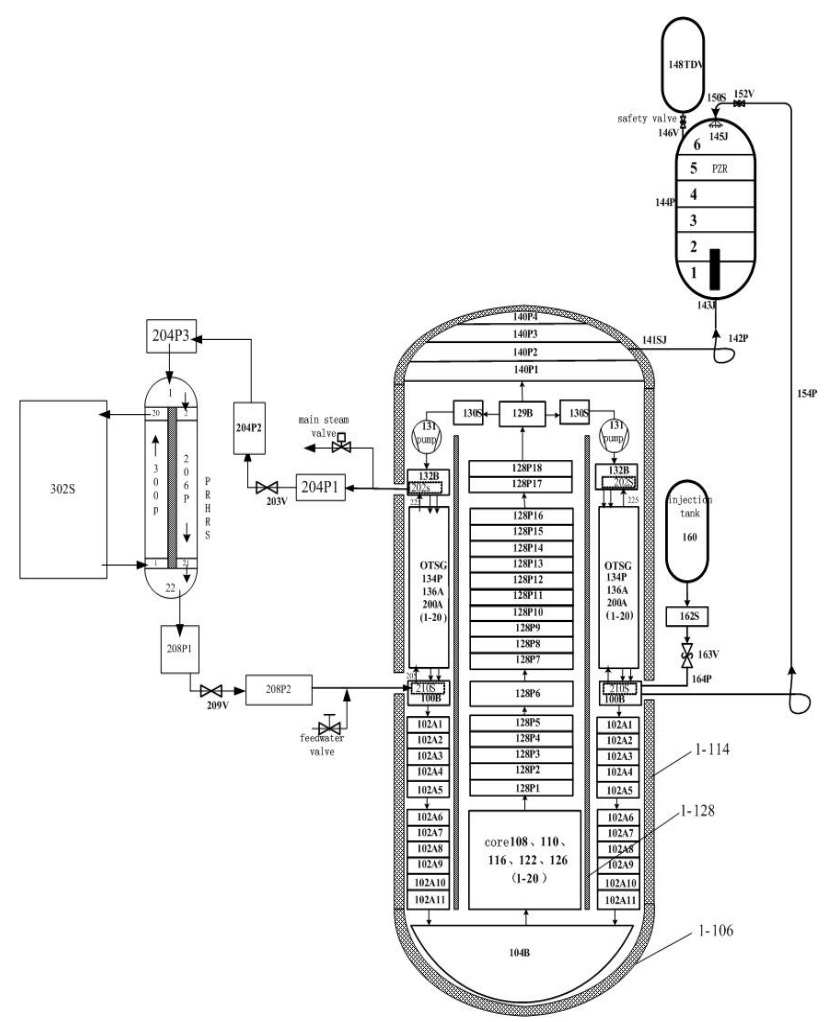

Figure 2. The nodalization for integral reactor. 


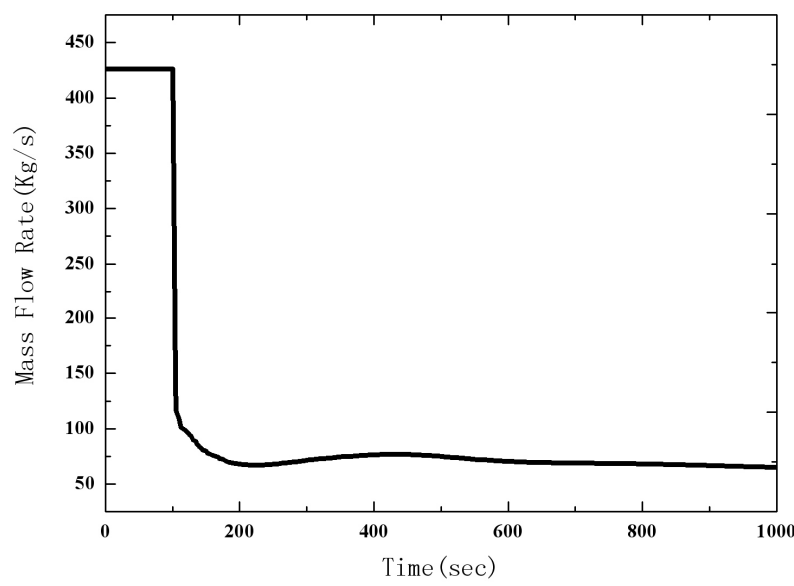

Figure 3. Mass flow rate in the primary loop.

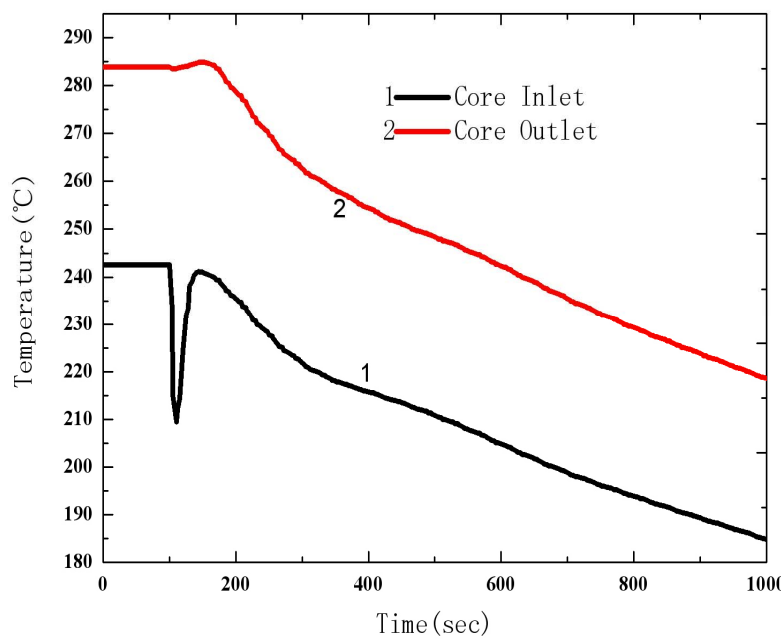

Figure 4. Fluid temperature at the core inlet, outlet.

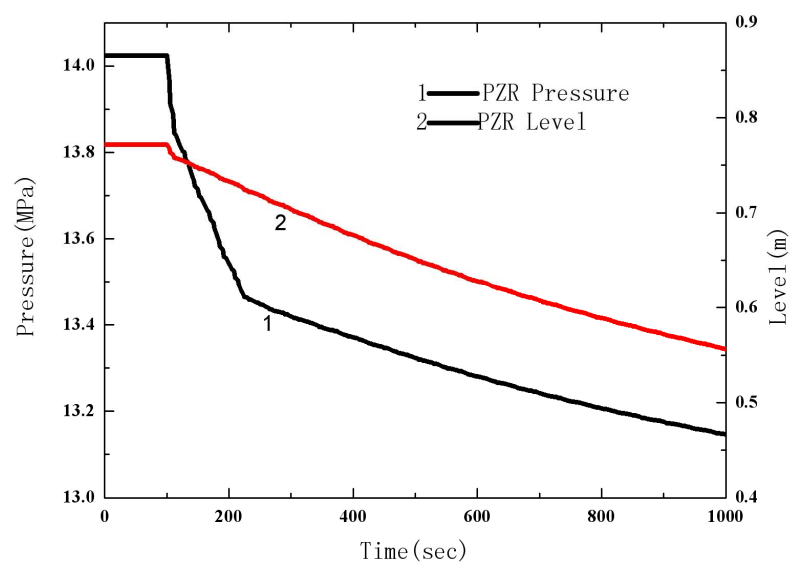

Figure 5. The pressure and water level in the pressurizer.

are increasing at the outlet of OTSG in the secondary loop. The secondary pressures thus continue to increase for a short period until the natural circulation establishes in the PRHRS loops. Figure 7 shows the heat generated in the core, the heat removed from the primary side to the steam generator and from the steam generator to the ultimate heat sink by the PRHRS during the accident. As shown in Figure 7, the heat transferred to the secondary and third sides exceeds the decay heat generated in the core after the PRHRS comes into operation, thus proving the capacity of the PRHRS in mitigating the marine black out accident.

Figure 8 shows the coolant temperature at the core inlet and outlet, which continues to decrease with decreased power after the natural circulation flow established well in the PRHRS loops (Reactor trip at $0 \mathrm{~s}$ ). When the coolant temperature reaches the SCS entry condition, which is $208^{\circ} \mathrm{C}$ of the coolant temperature at core outlet, the saturation temperature decreases rapidly due to a decreasing system pressure as shown in Figure 9, which is depressurized by an operator's action using an operation of the reactor coolant gas vent system (RCGVS).The pressurizer pressure begins to decrease

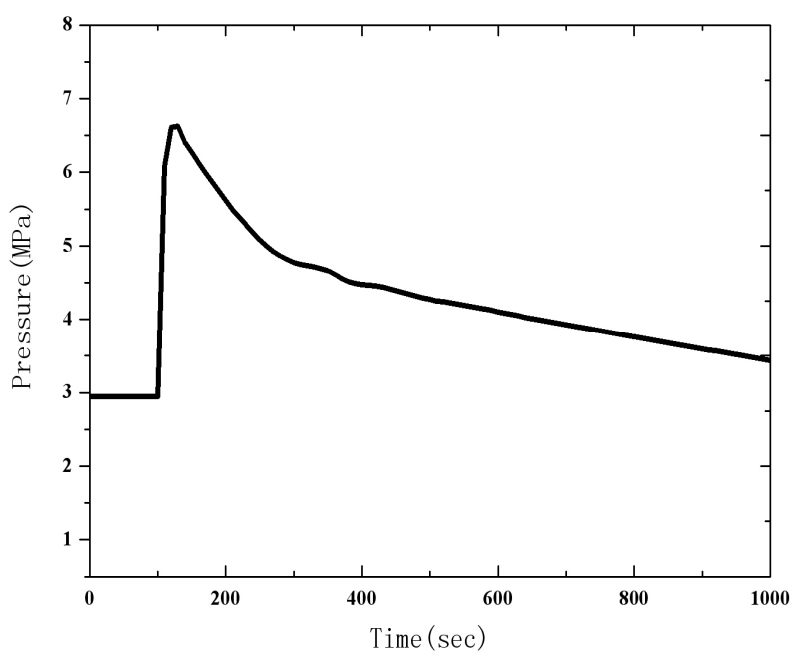

Figure 6. Outlet pressure of the OTSG secondary side.

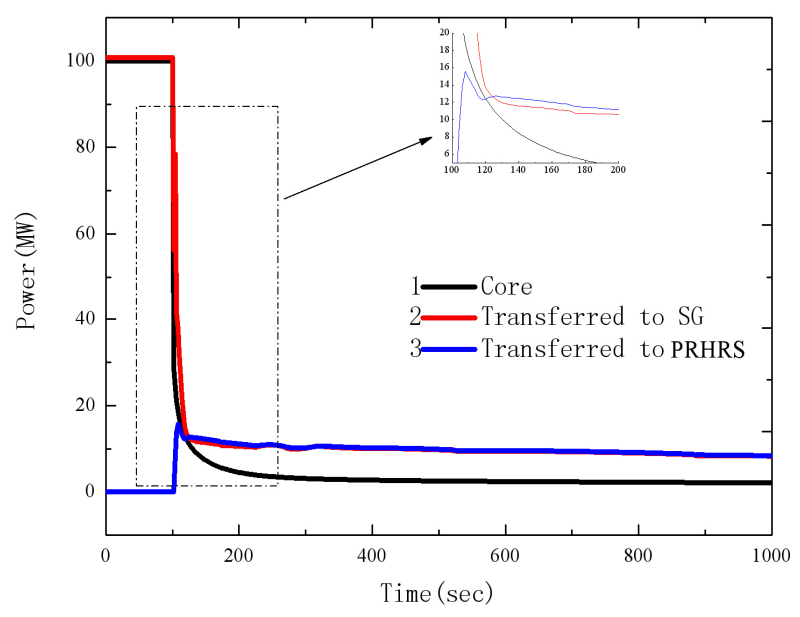

Figure 7. Comparison among the powers of the three loops. 
rapidly with the transient and then, it stabilizes at 9MPa. The system condition needs to be lower than $208^{\circ} \mathrm{C}$ and $2.3 \mathrm{MPa}$ in order to connect the SCS. The reactor coolant gas vent system is operated to achieve these conditions when the coolant temperature reaches $208^{\circ} \mathrm{C}$. Then, the system pressure decreases rapidly again to $2.3 \mathrm{MPa}$ as shown in Figure 9.

A sensitivity study is performed to establish the cooldown capability of the $100 \mathrm{MW}$ integral reactor for various system conditions such as natural and forced circulation conditions, and the number of PRHRS. The results are shown in Figure 10.

The pn, pf, sn and the sf denote a natural circulation at the primary system, a forced circulation at the primary system, a natural circulation at the secondary and a forced circulation at the secondary system, respectively. The forced circulation at the primary system is a case where the main coolant pump is available after a reactor is tripped and the forced circulation at the secondary system is a case where $10 \%$ of the normal feed-water flow rate is supplied by a feed-water pump. For the primary forced circulation condition, the coolant temperature

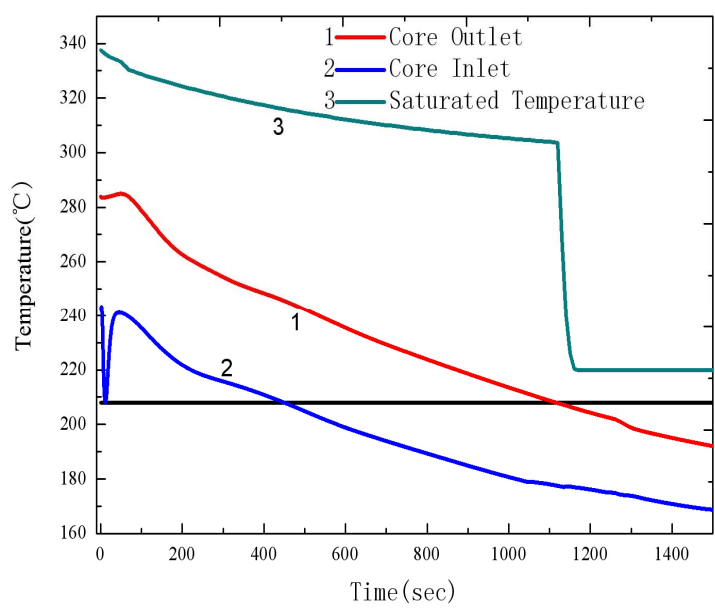

Figure 8. Primary system coolant temperature.

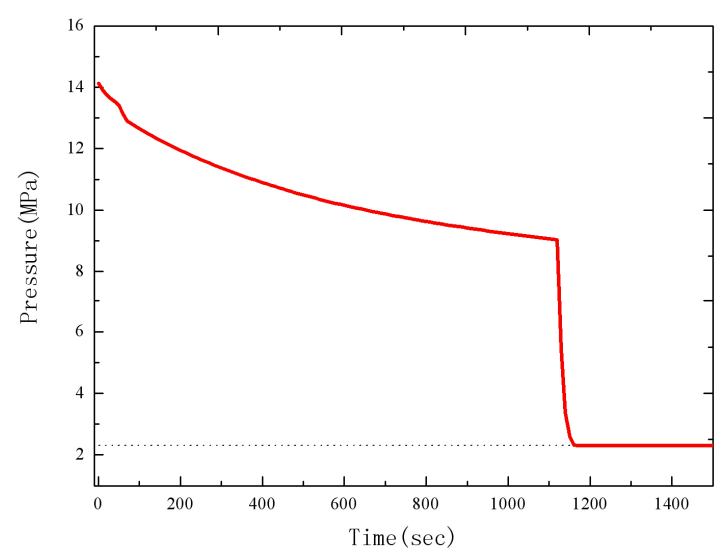

Figure 9. Pressurizer pressure.

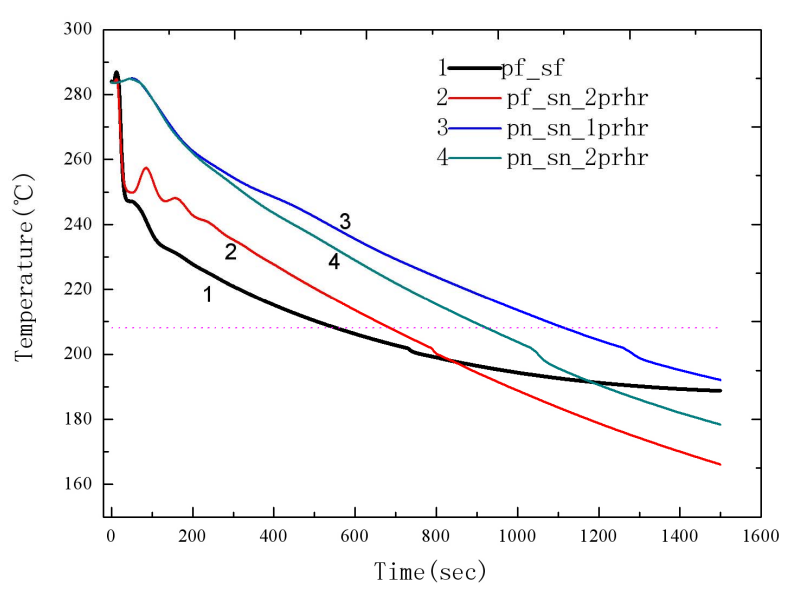

Figure 10. Coolant temperature for the sensitivity study.

of the primary system reaches the primary system entry condition nearly at the same time as the reference calculation. The cooldown capability of the IPWR is depend on the primary system condition, that is, a heat transfer at the steam generator primary side. Also, the coolant temperature can be cooled to $208^{\circ} \mathrm{C}$ by only one t PRHRS. However, it takes about $1100 \mathrm{~s}$ to reach the SCS entry condition.

\section{Summary and Conclusions}

The passive cooldown characteristics and the natural circulation performance of IPWR with a PRHRS have been investigated in the case of the marine black out accident. It is shown that the reactor coolant system and the PRHRS adequately remove the core decay heat, and assure to remove appropriately a heat capacity in the reactor vessel by natural circulation. For the design bases accident conditions, IPWR cools down the coolant to the SCS entry condition within $1100 \mathrm{~S}$ for all the possible boundary conditions. Furthermore, the system can reach the SCS entry condition by using only one PRHRS. Also, the safety systems function properly and thus they can secure the reactor to a safe condition for any accident.

\section{Acknowledgements}

Dai Shoubao would like to take this chance to express my sincere gratitude to my supervisor, Jin Chunnan and Chen Yuxiang, who provide the kindly assistance and valuable suggestions during the process of this paper.

This gratitude also extends to the professor Peng Minjun who taught him during his undergraduate years for his kind encouragement and patient instructions.

\section{REFERENCES}

[1] Y.-J. Chung, H.-C. Kim and B.-D. Chung, "Two Phase Natural Circulation and Heat Transfer in the Passive 
Residual Heat Removal System of an Integral Type Reactor," Annals of Nuclear Energy, Vol. 33, No. 3, 2006, pp. 262-270. doi:10.1016/j.anucene.2005.09.009

[2] M. H. Chang, S. K. Sim, D. J. Lee, "SMART Behavior under Over-Pressurizing Accident Conditions,” Nuclear Engineering and Design, Vol. 199, No. 1-2, 2000, pp. 187-196. doi:10.1016/S0029-5493(99)00068-0

[3] S. L. Cheng and G. J. Leng, "Inherent Safe UZrHx Power Reactor INSURE-100 Preliminary Research,” Nuclear Power Engineering, Vol. 15, No. 4, Aug. 1994.

[4] J. K. Liu and C. B. Tang, "Summarisation on Russian ABV-6M Integral Pressurized Water Reactor," Nuclear
Power Engineering, Vol. 18, No. 3,1997.

[5] Y. J. Chung, S. H. Kim and H. C. Kim, "Thermal Hydraulic Analysis of SMART for Heat Removal Transients by a Secondary System," Nuclear Engineering and Design, 2003, pp. 225-257.

[6] Y.-J. Chung and S. W. Lee, "Passive Cooldown Performance of a 65 MW Integral Reactor," Nuclear Engineering and Design, Vol. 238, 2008, pp. 1681-1689. doi:10.1016/j.nucengdes.2007.12.008

[7] C. D. Fletcher and R. R. Schultz. RELAP5/MOD3 Code Manual Volume V: USER' S GUIDELINES[Z], 1995, 38-42, 130-133, 139-158, 173-180. 